\title{
From Early Sensory Specialization to Later Perceptual Generalization: Dynamic Temporal Progression in Perceiving Individual Threats
}

\author{
Elizabeth A. Krusemark ${ }^{1}$ and Wen $\mathrm{Li}^{1,2}$ \\ ${ }^{1}$ Department of Psychology, University of Wisconsin, Madison, Wisconsin 53706, and ${ }^{2}$ Waisman Center, University of Wisconsin, Madison, Wisconsin \\ 53705
}

Threat evokes a variety of negative emotions such as fear, anger, and disgust. Whereas they elicit distinct and even opposite facial, sensory, and autonomic reflexes, threat-related emotions often converge in the actions they prompt (e.g., negative evaluation and avoidance). Here, we tested a unifying hypothesis that threat processing initially involves specialized encoding of individual subtypes to support discrete reflexive operations that later gives way to generalized elaborate analysis to facilitate convergent defensive behavior. Combining event-related potentials (ERPs) and a defensive context in human subjects, we compared temporal courses of perceptual analysis of two threat subtypes - fear and disgust. Indeed, fear enhanced and disgust suppressed early (115 ms) response in visual cortex, accentuating specialized sensory encoding of threat subtypes in accordance with the opposite behavioral and autonomic reflexes they typically elicit. By contrast, later ERP waveforms evoked by fear and disgust merged gradually over time (130-425 ms). Consistently, visual ERPs to anthropomorphic Greeble objects presented after fear versus disgust images also overlapped despite their clear departure from the neutral condition, paralleled by comparable exaggeration in Greeble imminence perception in the two threat (vs neutral) conditions. This later confluence of neural and behavioral response between fear and disgust thus highlights general threat categorization in high-level, downstream perception of threat. By delineating the temporal dynamics in perceiving individual threat emotions, our findings thus provide some of the first evidence to reconcile multidimensional and unidimensional aspects of information processing within the domain of threat, shedding new light on symptom heterogeneity across the anxiety disorder spectrum.

\section{Introduction}

Threat is typically associated with heightened neural and autonomic responses (LeDoux, 2000; Dolan, 2002; Phelps, 2006). However, such conceptualization fails to account for the diverse subtypes of threat capable of evoking heterogeneous and even opposite response profiles. In contrast to fear that provokes the sympathetic nervous system to prepare the body for fight or flight, disgust (another primary threat subtype) activates the parasympathetic system, facilitating freezing and fainting behavior (Ekman et al., 1983; Gray, 1987; Rozin and Fallon, 1987). These contradictory yet adaptive autonomic reflexes also coincide with opposing biomechanical properties of facial expressions of fear and disgust. Fearful expressions encompass widened eyes and nostrils to enhance sensory acquisition, whereas disgust expressions entail narrowed eyes and nostrils to impede sensory

Received March 19, 2012; revised Nov. 5, 2012; accepted Nov. 7, 2012.

Author contributions: W.L. and E.A.K. designed research; E.A.K. performed research; E.A.K. and W.L. analyzed data; W.L. and E.A.K. wrote the paper.

This research was supported by NIH Grants R01MH093413 (W.L.), P30HD03352 (W.L.), and T32MH018931 (E.A.K.). We thank Rick Jenison and Lucas Novak for their assistance with data analysis and Tobias Egner for helpful comments.

The authors declare no competing financial interests.

Correspondence should be addressed to either Elizabeth A. Krusemark or Wen Li, Department of Psychology, Brogden Hall, University of Wisconsin, Madison, WI53706, E-mail: ekrusemark@wisc.edu or wenli@psych.wisc.edu. DOI:10.1523/JNEUROSCI.1379-12.2013

Copyright $\odot 2013$ the authors $\quad 0270-6474 / 13 / 330587-08 \$ 15.00 / 0$ intake (Susskind et al., 2008). In keeping with this, recent neural evidence demonstrates that these two threat subtypes incite qualitatively different basic sensory responses in the extrastriate visual cortex (Krusemark and Li, 2011), resulting in amplified versus suppressed early visual response in fear and disgust, respectively, along with opposing effects on bottom-up visual spatial attention. These disparate response patterns within the threat domain therefore accentuate the need to characterize threat processing beyond an overarching unidimension of response amplification (represented almost exclusively by fear processing).

Nevertheless, the prevalent unidimensional theorization of threat processing holds true in many situations where we consistently observe convergent actions in response to fear and disgust stimuli (e.g., negative evaluation and affect; avoidance behavior). Presumably, high-level perception and cognition are evolutionarily pressed to culminate in motivationally appropriate actions (Bruner and Minturn, 1955; Gibson, 1979; Lang et al., 1997) and, as such, cognitive analysis of hedonically salient stimuli could be especially malleable to accommodate biological needs of the organism. Therefore, despite highly specialized sensory encoding, disgust and fear perception at later phases could converge to facilitate similar defensive responses (Gray, 1987; Rozin and Fallon, 1987; McNaughton and Corr, 2004). This dynamic progression would represent an extraordinary feat of the visual and emotion systems in the brain, maintaining a relatively fixed, labeled line of threat representation in sensory processing to pre- 
serve sensory fidelity and subtype-specific reflexes while permitting flexible higherorder perceptual processing to support a rich assortment of adaptive actions in various biological environments. However, this evolving process remains obscure; how would early sensory specialization of threat subcategories give way to later generalized analysis?

Toward this end, we modeled a defensive context by presenting neutral, anthropomorphic Greeble objects of varying sizes after fear, disgust, and neutral images. Combining high-density event-related potentials (ERPs) with cortical source estimation, we tested the hypothesis that ERP waveforms would demonstrate early specialization of visual encoding of fear and disgust images,

followed by a trend to progressively merge these two conditions over time. Importantly, we predicted that visual ERPs to ensuing Greebles would also overlap between the threat subtypes, accentuating general visual perturbation due to threat stimuli at later stages. Finally, we anticipated that fear and disgust would similarly exaggerate perceived Greeble imminence, provoking overlapping defensive behavior (Fanselow and Lester, 1988; McNaughton and Corr, 2004).

\section{Materials and Methods}

\section{Participants}

Forty right-handed students with normal or corrected to normal vision participated in the study. All participants denied a history of neuropsychological trauma or current use of psychotropic medication. One participant with extreme behavioral responses ( $>3 \mathrm{SD}$ ) was not included, resulting in a final sample of 39 participants (mean age: 19.19 years, 6 men). All participants provided informed consent, which was approved by the University of Wisconsin Institutional Review Board.

\section{Stimuli}

Emotion images. Images of natural objects were selected from the International Affective Picture Set (IAPS; Lang et al., 2008) to convey fear (IAPS 1012, 1050, 1201, 1120, 6260, 6263; depicting snakes, spiders, and guns), disgust (1274, 7380, 9300, 9302, 9322, and two non-IAPS images; depicting roaches, feces, and vomit), or neutral (1450, 1640, 1670, 7010, $7021,7025,7030,7035,7045,7053$; depicting animals and artifacts) content. Independent ratings of these images on valence, arousal, fear, and disgust dimensions using a visual analog scale (VAS) confirmed that the picture sets evoked the intended emotions (Krusemark and Li, 2011).

To establish the validity of the emotion picture sets among the participants, we acquired a set of ratings of the images at the end of experiment. On a visual analog scale of 0 (not at all) to 10 (extreme), participants rated fear images as highly frightening [6.45(2.35)] and disgust images equally highly disgusting [6.63(2.39); $\left.t_{(38)}=0.76, p=0.45\right]$, which were both above ratings for their alternate emotions [disgust rating for fear images: 2.92(2.48); fear rating for disgust images: 3.08(2.12); $p$ values $<0.001$ ]. Neutral images evoked very little fear $[0.43(0.61)]$ or disgust [0.23(0.49)]. On a VAS of -10 (extremely unpleasant) to +10 (extremely pleasant), participants further validated that fear and disgust images had equivalent affective values [fear: $-5.38(2.69)$; disgust: $\left.-5.30(2.37) ; t_{(38)}=0.24, p=0.81\right]$, both more negative than neutral images [1.99(1.66); $t_{(38)}$ values $<-15.18, p$ values $<0.001$ ]. Finally, fear images provoked the highest arousal [4.33(3.01)], followed by disgust images $\left[1.18(1.91) ; t_{(38)}=9.70, p<0.001\right]$ and the lowest arousal for neutral images $\left[-2.94(2.27) ; t_{(38)}=7.84, p<0.001\right.$; arousal rating range: \pm 10$]$. These valence and arousal patterns thus were compatible with the nature of the intended emotions (Ekman et al., 1983).

As early visual ERPs are sensitive to low-level physical differences in the stimuli, we carefully matched the image sets for basic visual properties, including spatial frequency, luminance, gray scale, and size (see
Krusemark and Li, 2011). We also conducted a control ERP experiment using Fourier phase-scrambled versions of the emotion images that evoked equivalent visual ERP waveforms across the three image sets, further ruling out such confounds (Krusemark and Li, 2011).

Greeble images. Greebles are a set of novel anthropomorphic objects that have been used as comparison stimuli in electrophysiological examinations of face processing (Gauthier and Tarr, 1997). Due to their novelty and face-like formations, we decided to employ Greeble objects $(n=30)$ as targets in the distance judgment task. These Greebles appeared in one of four sizes (subtending $6.29^{\circ} \times 5.34^{\circ}, 5.11^{\circ} \times 4.77^{\circ}, 4.86^{\circ} \times 4.05^{\circ}$, and $4.15^{\circ} \times$ $3.58^{\circ}$ of visual angle, from largest to smallest) with equal probability. An independent sample $(N=22)$ rated these Greeble images on a VAS ranging from -10 (extremely unpleasant) to +10 (extremely pleasant), establishing that these images were neutral $[M(\mathrm{SD})=-0.24(1.15)$, $\left.t_{(21)}=-0.98, p=0.34\right]$.

\section{Distance judgment task}

Participants were seated in a dimly lit room during the task, approximately $120 \mathrm{~cm}$ from a CRT monitor. Each trial began with a crosshair presented at the center of the screen, followed by a centrally presented emotion image displayed for $240 \mathrm{~ms}$, subtending a visual angle of $7.2^{\circ} \times$ $7.2^{\circ}$. Following a jittered interval lasting from 13 to $347 \mathrm{~ms}$ (eight different durations:13, 40, 93, 147, 200, 240, 293, and $347 \mathrm{~ms}$ with equal probability) that was designed to dissociate ERPs between the two successive stimuli, a Greeble image was displayed randomly in one of the four sizes for $400 \mathrm{~ms}$. Subsequent to Greeble onset, individuals were instructed to respond as quickly and accurately as they could to indicate how close or distant the Greeble appeared to be on a two-polar, six-point scale $(1=$ closest, 6 = farthest; response buttons counterbalanced across participants; Fig. 1). Egocentric distance judgments of Greebles were used to index perceived object imminence that could reflect behavioral avoidance (Fanselow and Lester, 1988; McNaughton and Corr, 2004). Two blocks, each consisting of 150 trials from the three emotion conditions, were randomly presented (totaling 100 trials per emotion). Greeble stimuli were counterbalanced according to emotion conditions. Participants performed this experiment after a separate visual search task involving horizontal and vertical bars (Krusemark and Li, 2011).

\section{EEG recording and data analysis}

EEG was recorded from a 96-channel (BioSemi ActiveTwo) system at a $1024 \mathrm{~Hz}$ sampling rate with a 0.1 to $100 \mathrm{~Hz}$ bandpass filter. Electrooculograms (EOGs) were recorded at two eye electrodes at the outer canthi and one infraorbital to the left eye. EEG signals were referenced offline to the average of the left and right mastoid recordings. Horizontal EOG channels were referenced to each other, and the vertical EOG channel was referenced to the EEG channel located directly above it. EEG/EOG signals were digital bandpass filtered from 0.1 to $40 \mathrm{~Hz}$, down-sampled to $256 \mathrm{~Hz}$, segmented around picture onset (from $-200 \mathrm{~ms}$ to $400 \mathrm{~ms}$ ) and Greeble onset ( -100 to $400 \mathrm{~ms}$ ), and corrected to the respective 200/100 
ms pre-stimulus baseline. Trials with EEG/EOG voltages exceeding \pm 75 $\mu \mathrm{V}$ (relative to baseline) were excluded from analysis.

Stimulus presentation was linked to the refresh rate $(75 \mathrm{~Hz})$ of the CRT screen and delivered using Cogent2000 software (Wellcome Department of Imaging Neuroscience, University College London, London, UK) as implemented in Matlab (MathWorks). Event synchronization was verified by placing a photodiode at the center of the CRT monitor sampled by the EEG acquisition computer, determining image onset consistently aligned with the event trigger across repeated trials (Krusemark and Li, 2011).

\section{Response to IAPS images}

The P1 ERP component is a well-accepted index of early visual perception, including emotion perception (Mangun et al., 1993; Pizzagalli et al., 1998; Eimer and Holmes, 2007; Vuilleumier and Pourtois, 2007; Li et al., 2008a; Forscher and Li, 2012), and was thus adopted in our previous study to characterize threat specialization in early visual analysis (Krusemark and Li, 2011). Here, the P1 component was extracted to replicate our earlier finding. Inspection of the grand average waveforms indicated a distinct $\mathrm{P} 1$ component that peaked at $115 \mathrm{~ms}$ post-image onset, maximal at central occipital sites (Oz; Fig. $3 A, B)$. Mean P1 amplitudes were extracted at the central occipital locus (collapsed across five electrodes surrounding $\mathrm{Oz}$ ) over $36 \mathrm{~ms}$ intervals centered on the peak (i.e., peak \pm 4 samples). To describe the temporal evolution of visual processing of these threat subtypes following basic sensory encoding, we examined electrical signals at this occipital site from the conclusion of the P1 window $(130 \mathrm{~ms})$ to the (average) Greeble onset $(425 \mathrm{~ms})$. Using a datadriven approach, we submitted voltage amplitude at each data point (out of a total of 75 points) to paired $t$ tests (comparing fear vs disgust, fear vs neutral, and neutral vs disgust) to depict the relationship dynamics among these stimuli over time. To minimize type I error, a corrected $p<$ 0.05 was set based on a Monte Carlo simulation using the AlphaSim program (http://afni.nimh.nih.gov/afni/doc/manual/AlphaSim) incorporating the autocorrelation and variance across the time points-results exceeding the threshold of $p<0.01$ over six consecutive data points were specified as statistically significant.

\section{Response to Greeble images}

As face-like Greebles reliably elicit face-related visual ERPs, including P1 and N170 (Rossion et al., 2002), these two visual ERPs were extracted and submitted to statistical analyses. In keeping with the fact that face processing is strongly lateralized (Kanwisher et al., 1997), the P1 and N170 responses to Greebles were maximal at lateral rather than at midline sites. We thus considered the two hemispheres separately in the Greeble analysis.

Greeble images evoked a distinct P1 component peaking at $112 \mathrm{~ms}$ post-Greeble onset (P1g), maximal at lateral occipital sites O1 (left hemisphere) and $\mathrm{O} 2$ (right hemisphere; Fig. $4 A-C$ ). We extracted P1g mean amplitude at each bilateral locus (collapsed across two electrodes surrounding the $\mathrm{O} 1 / \mathrm{O} 2$ sites) over $36 \mathrm{~ms}$ intervals centered on the peak (i.e., peak \pm 4 samples).

A clear N170 component in response to Greeble images was identified, peaking at $154 \mathrm{~ms}$ post-Greeble with maximal negative voltage at bilateral sites P7 (left hemisphere) and P8 (right hemisphere). Mean N170 amplitudes were extracted (collapsed across five electrodes surrounding the P7/P8 loci; see Fig. $4 E, G$ ) over $44 \mathrm{~ms}$ intervals centered on the peak (i.e., peak \pm 5 samples). Since the current investigation focused on visual perception of emotion, events beyond Greeble P1 and N170 were out of the scope of interest (especially given that the later waveforms conformed to the P1 and N170 components) and thus were not specifically described.

\section{Low resolution brain electromagnetic tomography}

We isolated the cortical sources of significant ERP effects using low resolution brain electromagnetic tomography (LORETA: Pascual-Marqui et al., 2002). As an inverse solution, LORETA has been validated using neuroimaging in visual and cognitive processes. LORETA uses a threeshell spherical head model registered to standardized space from a digitized MRI at the Montreal Neurological Institute (MNI). Solutions are restricted to cortical gray matter, spanning 2394 voxels with a spatial resolution of $7 \times 7 \times 7 \mathrm{~mm}^{3}$. We estimated voxelwise current densities during respective intervals for each subject in response to fear, disgust, and neutral conditions that were then submitted to voxelwise statistical analyses. To minimize false positives in intracranial source localization, we applied two constraints in our analysis. First, we constrained LORETA analysis to the time windows and tests where surface ERP effects were significant (Thatcher et al., 2005). Second, based on the actual voxel spatial correlation in the current dataset, we conducted a Monte Carlo simulation in AlphaSim to set a corrected statistical threshold of $p<0.05$. Applying the actual Gaussian filter widths (FWHMx $=4.02 \mathrm{~mm}$, FWHM $y=4.68 \mathrm{~mm}, \mathrm{FWHM} z=3.76 \mathrm{~mm})$, the actual voxel size $(7 \times$ $\left.7 \times 7 \mathrm{~mm}^{3}\right)$, and a connection radius $(7 \mathrm{~mm})$, we derived a corrected threshold consisting of a voxel level $p<0.005$ over three contiguous voxels. All coordinates are reported in MNI space.

\section{Statistical analysis}

We first validated the paradigm using one-way repeated measures analyses of variance (ANOVAs; with Greenhouse-Geisser corrections) of Greeble size on distance judgments and response time (RT). Then, twoway repeated-measures ANOVAs (emotion by Greeble size) were performed on distance judgments, P1 and later ERPs to IAPS pictures. Lastly, three-way repeated-measures ANOVAs (emotion by Greeble size by hemisphere) were performed on P1g and N170 amplitudes. Significant ANOVA effects were followed by $t$ tests to contrast different experimental conditions (using the least significant difference test, LSD). Analysis of later ERPs (from post-P1 to Greeble onset) was also performed using a data-driven approach as mentioned above. RTs over \pm 2 standard deviations from the mean were excluded, and remaining RTs were log-transformed before analysis to reduce skewness.

\section{Results}

\section{Paradigm validation}

We adopted an imminence manipulation to elicit defensive responses. Due to the high temporal sensitivity of electrophysiological recordings, we chose to apply a static Greeble image on a given trial (rather than moving or shrinking/expanding objects in typical looming paradigms) to ensure precise Greeble locking while varying Greeble sizes across trials to manipulate object imminence. Below, we established our imminence manipulation by demonstrating defensive avoidance in participants as Greebles grew bigger in size.

A one-way ANOVA of Greeble size as the independent variable (trials were collapsed across all emotion conditions) indicated that the object was perceived to be systemically more proximal with increasing size $\left[F_{(1.10,41.87)}=118.38, p<0.001\right.$, $\eta^{2}=0.76$; Fig. $\left.2 A\right]$. From the smallest to the largest size, estimated egocentric distance $[M(\mathrm{SD})]$ decreased linearly [4.11(0.81), 3.19(0.60), 2.39(0.67), and 1.80(0.84)], differing significantly between any two sizes $\left[t_{(38)}\right.$ values $>9.97, p$ values $<$ $0.001, d$ values $>1.5]$. RT results paralleled the distance judgment: larger Greeble size led to faster response in a monotonic fashion $\left[F_{(1.69,64.24)}=22.76, p<0.005, \eta^{2}=0.38\right.$; Fig. $\left.2 B\right]$. From the largest to the smallest size, RT was $796 \mathrm{~ms}$ (135), $825 \mathrm{~ms}$ (146), $854 \mathrm{~ms}$ (163), and $884 \mathrm{~ms}$ (155), respectively. All pairwise RT contrasts were significant, $t_{(38)}$ values $>3.12$, $p$ values $<0.01$, $d$ values $>0.48$. Furthermore, RT and distance judgment were closely correlated, $r=0.45, p=0.005$, with greater proximity being associated with faster speed. Finally, consistent with the fact that defensive responses tend to be exacerbated in anxiety, we observed close correlations between these measures and anxiety severity (measured by the Beck Anxiety Inventory; Beck et al., $1988)$; higher anxiety was associated with increased proximity $(r=-0.35, p<0.05)$ and faster reaction time $(r=-0.33, p<$ $0.05)$. Therefore, these findings align with the account of "defensive distance" that imminent novel objects evoke defensive response, providing coherent support for our paradigm at 
effectively provoking the defense system (Fanselow and Lester, 1988; McNaughton and Corr, 2004).

\section{Behavioral evidence: fear and disgust images similarly increased Greeble imminence}

Within such a defensive context, threat emotion exerted a significant effect on estimated Greeble imminence, $F_{(1.67,63.35)}=$ 8.02, $p=0.001, \eta^{2}=0.18$. Greebles following fear and disgust images appeared closer [fear: $M(\mathrm{SD})=2.86(0.58)$; disgust: $2.84(0.57)]$ than did those following neutral images $\left[2.96(0.55) ; t_{(38)}\right.$ values $<-2.86, p$ values $<0.01, d$ values $>$ 0.45; Fig. $2 C$ ], but there was no difference between fear and disgust conditions, $p=0.51$. This emotion effect was somewhat independent of Greeble size, $p=0.15$. Post hoc analyses showed that at a trend level, the linear effect of Greeble size (greater size $\rightarrow$ greater proximity) was more prominent in the threat (fear and disgust combined) than neutral condition, $t_{(38)}=-1.68, p=0.10$, albeit the two threat conditions did not differ, $p=0.45$. Overall, our behavioral results suggest that fear and disgust emotions comparably increased perceived proximity of Greeble objects, marking convergent perceptual consequences of the two threat subcategories.

\section{Neural evidence (1): fear and disgust images elicited distinct P1 response}

Replicating our previous finding (Krusemark and Li, 2011), a significant effect of emotion emerged in P1 amplitude, $F_{(1.93,73.23)}=$ $19.14, p<0.001, \eta^{2}=0.34$ (Fig. $3 A, B$ ). Indicative of early divergence between fear and disgust emotions, fearful images evoked larger P1 amplitude $[M(\mathrm{SD})=5.94 \mu \mathrm{V}(4.00)]$ relative to neutral baseline images [ $5.18 \mu \mathrm{V}(4.33) ; t_{(38)}=2.47, p=0.02, d=0.39$ ], whereas disgust images suppressed $\mathrm{P} 1$ relative to neutral images [4.18 $\mu \mathrm{V}$ (4.15); neutral vs disgust: $t_{(38)}=3.51, p=0.001, d=$ 0.56 ; fear vs disgust: $t_{(38)}=6.83, p<.001, d=1.09$ ].

In light of the opposite patterns of P1 to fear and disgust conditions, we then searched for the neural substrates underlying such discrimination in LORETA. A voxelwise $t$ contrast of estimated current density (fear $>$ disgust) localized the source to the left fusiform gyrus [ 5 voxels, maximal at $-45,-39,-20$; $t_{(38)}=$ $4.58, p<0.005$; Figure $3 C$ ], exhibiting greater current density in response to fear over disgust images.

\section{Neural evidence (2): later ERP responses to fear and disgust images converged over time}

As illustrated in Figure 3, $A$ and $D$, our data-driven analysis of subsequent emotion perception (from post-P1 to Greeble onset: $130-425 \mathrm{~ms}$ post-image onset) revealed a steady course of augmented fear response relative to neutral images, spanning 182-210 ms post-image [ANOVA over this window: $F_{(1.84,69.82)}=$ 7.25, $\left.p=0.001, \eta^{2}=0.16\right]$ and 221-425 ms post-image [ANOVA over this window: $F_{(1.81,68.66)}=27.29, p<0.001, \eta^{2}=$ $0.42]$. Interestingly, the disgust waveform first overlapped with the neutral waveform but then (at 288-425 ms) rose above its counterpart [ANOVA over this window: $F_{(1.81,68.78)}=36.27, p<$ $.001, \eta^{2}=0.49$; Figure $\left.3 A, D\right]$. Importantly, the disgust waveform converged with the fear waveform toward the end of the observation window (388-425 ms). A 99\% confidence interval was plotted for each condition to provide a point-by-point illustra- tion of the dynamic relationships among the three emotion types (Fig. 3A).

Given the general departure of threat from neutral conditions in this later interval $(288-425 \mathrm{~ms})$, we examined the source of this effect (threat $>$ neutral) in LORETA. Source analysis revealed two voxels at $p<0.005$ in the right middle temporal gyrus (peak: $67,-32,-13$ ) and one in the left middle temporal gyrus $(-59,-39,-13)$. At a less stringent threshold of $p<0.01$, these two areas extended into bilateral fusiform regions [four voxels in the right hemisphere (cluster-level $p_{\text {corrected }}<0.05$ ) and three voxels in the left (cluster-level $p_{\text {corrected }}=0.19$ ); Figure $3 E$ ]. This analysis thus localized sources of this later threat processing to downstream visual cortical areas.

\section{Neural evidence (3): Greeble P1 and N170 overlapped between fear and disgust conditions}

Finally, we isolated Greeble-related visual ERPs (P1g and N170) to investigate how fear and disgust modulated visual processing of a subsequent novel anthropomorphic stimulus to provide supplemental information about threat-related impacts on perception. There was a main effect of emotion on P1g amplitude, $F_{(1.93,73.24)}=5.84, p<0.01, \eta^{2}=0.13$, and a significant emotion-by-hemisphere interaction, $F^{(1.90,72.29)}=3.99, p<0.05$, $\eta^{2}=0.09$ (Fig. $4 A, B$ ). The interaction was driven by a simple main effect of emotion at the right occipital $\mathrm{O} 2$ site $\left[F_{(1.86,70.61)}=9.11, p<\right.$ $\left.0.001, \eta^{2}=0.19\right]$. Emotion did not influence P1g amplitude at the left hemispheric $\mathrm{O} 1$ site $\left[F_{(1.99,75.85)}=1.84, p=0.17\right]$. Pairwise comparisons indicated differential P1g at $\mathrm{O} 2$ between neutral $[5.83 \mu \mathrm{V}$ (4.00)] and threat emotions [fear: $4.98 \mu \mathrm{V}$ (3.96); disgust: $4.83 \mu \mathrm{V}$ $(3.94) ; t_{(38)}$ values $>3.09, p$ values $<0.005, d$ values $\left.>0.48\right]$. Nevertheless, disgust and fear evoked comparable P1g potentials $\left[t_{(38)}=\right.$ $0.67, p=0.51$; Figure $4 C$ ]. Finally, there was no Greeble size effect (independent or interactive), $p$ values $>0.60$.

Similar to the P1g effect, there was a significant effect of emotion on N170 amplitude, $F_{(1.94,73.58)}=5.01, p<0.01, \eta^{2}=0.12$, and a significant emotion-by-hemisphere interaction, $F_{(1.84,70.01)}=$ 9.96, $p<0.001, \eta^{2}=0.21$. Follow-up ANOVAs revealed an emotion effect at the right hemispheric site, $\mathrm{P} 8\left[F_{(1.89,71.78)}=12.81\right.$, $p<.001, \eta^{2}=0.25$; Figure $\left.4 F, G\right]$, but not at the left hemispheric site, P7 $\left[F_{(1.99,75.75)}=0.28, p=0.79\right]$. Pairwise contrasts indicated comparable N170 amplitudes for fear and disgust trials [fear: $-0.53 \mu \mathrm{V}$ (2.72); disgust: $-0.26 \mu \mathrm{V}$ (2.82); $t_{(38)}=-1.22$, $p=0.23]$, which were significantly more pronounced than the $\mathrm{N} 170$ for neutral trials $\left[0.54 \mu \mathrm{V}(2.85) ; t_{(38)}\right.$ values $>3.65, p$ values $<0.001, d$ values $>0.58]$. Finally, except for an isolated trend-level main effect at P7 [ $p=0.07$; greater size $\rightarrow$ greater 


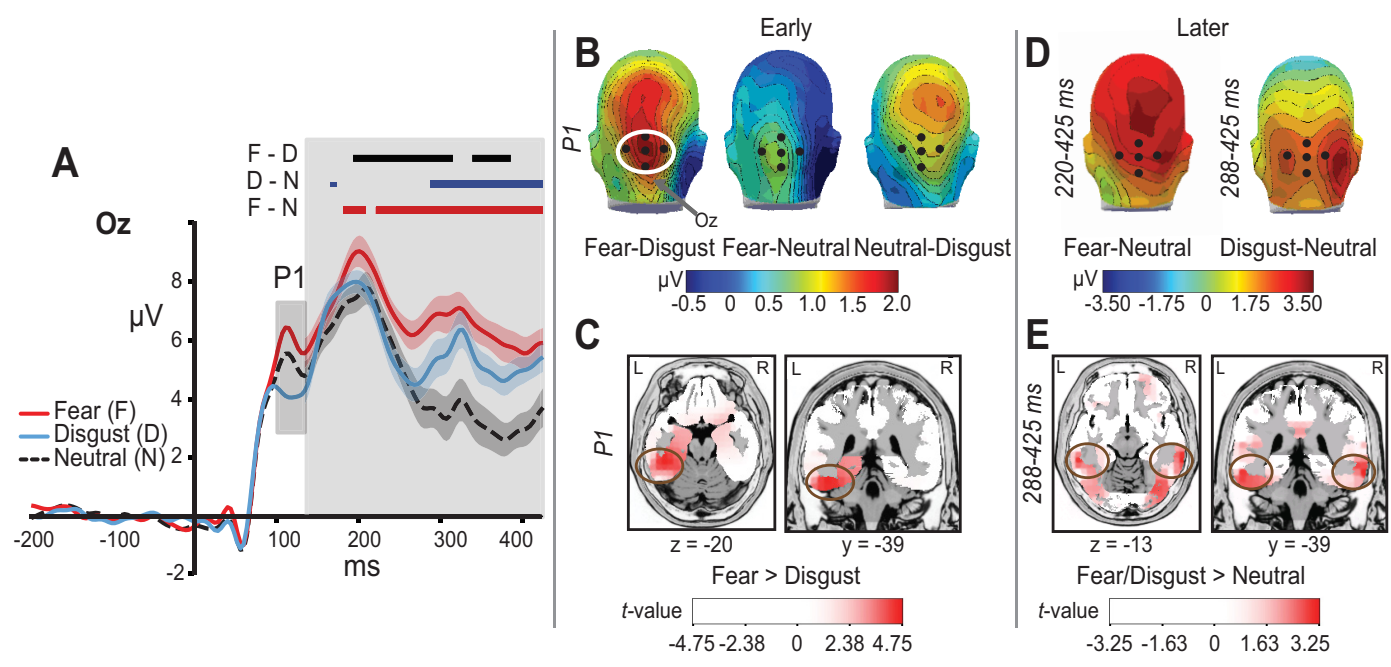

Figure 3. Neurophysiological responses to fear and disgust images. $A$, ERP waveforms at $0 z$ with shaded bands depicting $99 \%$ Cl for each condition. Windows with significant difference between any two conditions ( $F-D$, fear vs disgust; $D-N$, disgust vs neutral; $F-N=$ fear vs neutral) are indicated by lines at the top (thick lines, $>6$ consecutive data points; thin lines, $<6$ data points). $\boldsymbol{B}$, Scalp topographies of differential P1. The five encircled black dots represent 0z. C, LORETA source estimation isolated augmented current density for fear over disgust conditions in the left fusiform gyrus during the P1 interval. $\boldsymbol{D}$, Scalp topographies of differential response (fear/disgust - neutral; $>220 \mathrm{~ms}$ ). $\boldsymbol{E}$ LORETA revealed greater current density for threat than neutral conditions in bilateral middle temporal gyrus during the $288-425$ ms interval.
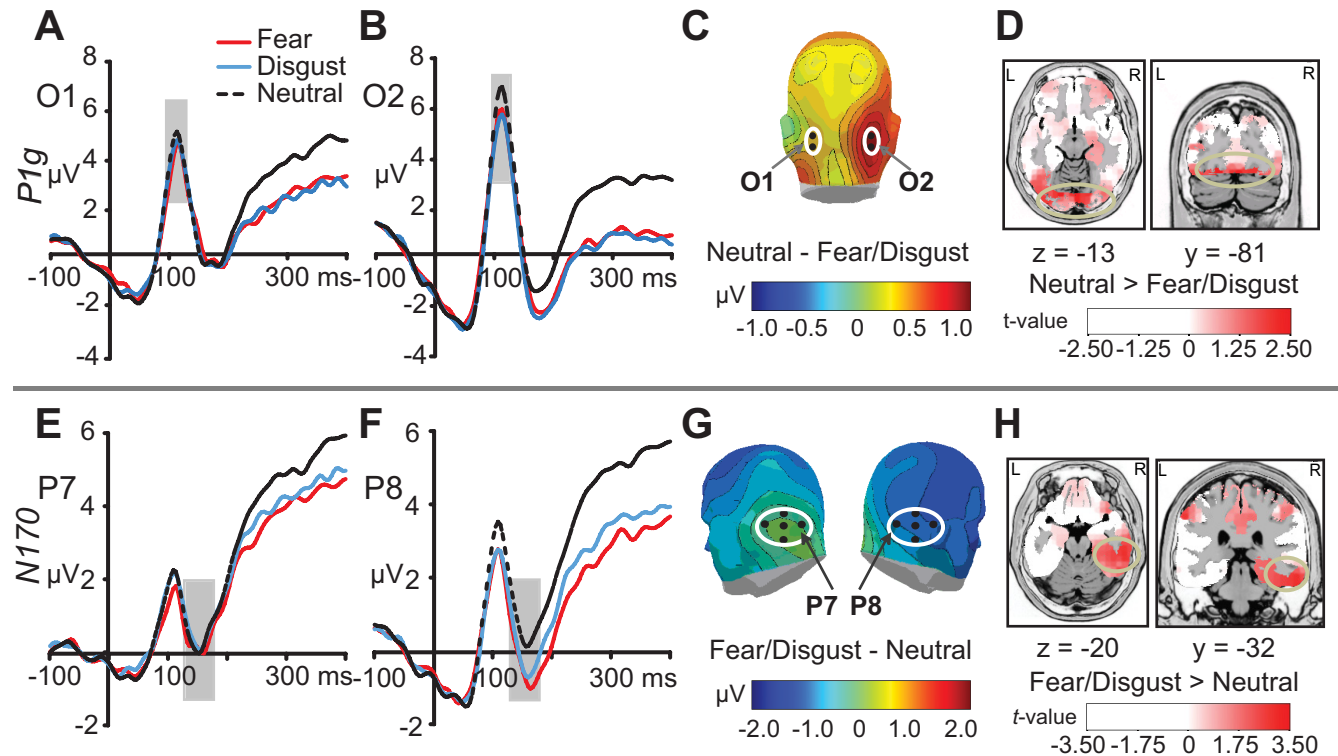

Figure 4. Convergent effects of threat (fear and disgust) on Greeble-related P1g and N170. A, B, P1g at $01(\boldsymbol{A})$ and $02(\boldsymbol{B})$ indicates overlapping waveforms for fear and disgust, which departed from the neutral condition at 02. C, Scalp topography of differential P1 $\mathrm{g}$ (neutral-threat). Black encircled dots indicate 01 and 02 sites. D, LORETA isolated (at a lenient threshold; $p<0.01$ ) greater current density in bilateral lingual gyri for neutral than threat conditions during the P1g interval. L, Left, R, right. $\boldsymbol{E}, \boldsymbol{F}, \mathrm{N} 170$ at sites $\mathrm{P7}(\boldsymbol{E})$ and $\mathrm{P8}(\boldsymbol{F})$ show convergence between fear and disgust, both exceeding the neutral condition at P8. G, Scalp topographies of differential N170 response (threat - neutral). Black encircled dots represent P7 and P8 sites. $H, L$ ORETA indicated greater current density in the right inferior temporal gyrus for threat compared to neutral conditions during the N170 interval.

N170], Greeble size did not influence N170, either independently or interactively.

Finally, exploratory trial-by-trial correlation analyses were conducted between perceived imminence and P1g and N170 amplitude, which yielded very weak associations $(r$ values $<$ $0.10)$. Given that perceptual decisions rely on long-latency rather than short-latency visual analysis (Jolij et al., 2011), the absence of tight relations between early visual ERPs and perceptual outcome was in concordance with this principle. We caution, however, that single-trial ERP data are often highly noisy, which could greatly attenuate correlations on a trial-bytrial basis.
Given that Greeble P1g and N170 effects were driven by differences between general threat and neutral conditions, our LORETA localization focused on the neural structures subserving differential processing of threat (fear and disgust combined) versus neutral information. Voxelwise comparisons in LORETA in the P1g window did not reveal any cluster meeting the preset statistical threshold. However, a few clusters ( $\geq 4$ voxels) in the extrastriate visual cortex emerged at a less rigorous threshold of $p<0.01$ (equivalent to cluster-level $p_{\text {corrected }}<0.05$; e.g., lingual gyrus centering on $-17,-81,-13$ and $18,-46,1$; Fig. $4 D$ ). In the N170 window, LORETA revealed a cluster in the right inferior temporal gyrus [five voxels, maximal at $60,-32,-20 ; t_{(38)}=$ 
$3.19, p<0.005$; Figure $4 H]$ with greater current density for threat emotions than the neutral condition. Again, threat, regardless of subtype, enhanced visual cortical activity.

\section{Discussion}

By examining two primary threat subtypes, fear and disgust, the current study provides some first evidence characterizing the temporal progression of visual perception of individual threat emotions. Despite early specialized encoding (115 ms), threat perception gradually fuses between fear and disgust (130-425 $\mathrm{ms})$. This later convergence was paralleled by overlapping visual response to and similar perceived proximity of Greebles that followed fear versus disgust images relative to the neutral condition. Therefore, threat perception systematically evolves from nuanced early specialization to generalized higher-order processing, promoting concordant defensive behavior to potential dangers. As such, these findings help reconcile the multidimensional view (with accumulating support) and the (currently dominant) unidimensional theorization of threat processing. This paradoxical temporal development has the potential to unify highly heterogeneous symptoms in psychopathologies such as anxiety disorders, thereby affording novel insights into clinical research and intervention. To the extent that fear heightens sensory processing and disgust dampens it, potentially driving distinct symptoms (e.g., obsessive worrying versus trauma-related amnesia) by influencing object encoding in opposite directions, the two threat subtypes also entail motivationally similar responses, fueling general avoidance behavior in anxiety.

As arousal can impact attention and motivation, it may contribute to the current ERP and behavioral effects, independent of specific emotions. However, we observed weak correlations between arousal ratings and the reported behavioral and ERP effects $(r$ values $=-0.18 \sim 0.26, p$ values $=0.11 \sim 0.60)$, suggesting that arousal-driven processes were unlikely to account for these results. Specifically, if arousal drove the P1 effect, then the greater arousal level of disgust (vs neutral) stimuli would contradict the suppressed P1 to disgust (vs neutral) images. If arousal underpinned later ERPs or ERPs or Greeble effects, then the significant disparity in arousal level for fear and disgust could not be reconciled with the convergent profiles for fear and disgust trials. Finally, underlying sources of scalp effects were localized in the extrastriate and fusiform cortices (as opposed to emotion/attention areas such as orbitofrontal and parietal cortices), further ruling out alternative accounts related to general arousal/attention influences. Additionally, all Greebles were rated as neutral and thus did not exert an emotion effect in and of themselves. To the extent that precision of temporal locking decays with increasing response latency, signal sensitivity of later ERPs to IAPS images could be somewhat blunted, potentially precluding the observation of fear-versus-disgust differentiation in the later window. However, this possibility is very low based on three facts: Firstly, these later ERP effects mirrored Greeble ERP effects that were closely time locked and possessed adequate signal sensitivity. Importantly, three lines of evidence related to later processing (later IAPS ERPs, Greeble ERPs, and behavioral judgments) converged on a general departure of threat from neutral conditions, providing solid support to the notion of generalized later threat processing. Secondly, the later threat convergence was driven by a sustained increase in response to disgust over time, substantiated by a series of significant effects (positive evidence). Thirdly, from the early opposite direction to the later same direction, the manner in which fear and disgust deviated from the neutral condition suggests that processing of specific threats evolved from being qualitatively distinct to qualitatively similar. Finally, all ERP effects reported here were localized to fairly close/overlapping visual cortices, largely eliminating the possibility that variable distances of neural substrates to the scalp and related signal sensitivity disparity contributed to these distinct ERP result patterns.

These results mapped precisely onto our previous finding of $\mathrm{P} 1$ enhancement in fear versus suppression in disgust (relative to neutral images; Krusemark and Li, 2011). That fear and disgust diverged in opposite directions relative to a neutral baseline around $100 \mathrm{~ms}$ highlights a qualitative characterization of individual threats in basic visual encoding, akin to the ecological function of sensory acquisition in fear versus rejection in disgust (Gray, 1987; Rozin and Fallon, 1987). Notably, in contrast to the current defensive context and a perceptual decision task, our previous study involved a low-level visual search task demonstrating divergent behavioral consequences of fear and disgust stimuli. Reliability of P1 discrimination despite these significant discrepancies in context, task demand, and behavioral outcomes accentuates the idea of mandatory specificity in sensory encoding of threat and its immunity to high-level motivational influences.

This early sensory encoding, supporting both response amplification and suppression in the visual cortex, extends beyond a generic gain increase in sensory and attentional processing of threat (Desimone and Duncan, 1995; Luck, 1995). Given that the amygdala often exhibits a general response augmentation to fear and, to a lesser extent, disgust stimuli (LeDoux, 1995; Anderson et al., 2003) and requires a response latency well over $100 \mathrm{~ms}$ (Oya et al., 2002; Krolak-Salmon et al., 2004), the current finding implicates specialized emotion processing systems outside the predominant amygdala pathways (LeDoux, 1995; Tamietto and de Gelder, 2010). That is, beyond amygdala threat processing via subcortical routes (Rotshtein et al., 2010; Garrido et al., 2012) and coarse threat decoding in the orbitofrontal cortex (Barrett and Bar, 2009) that pose general response amplification to threat by fast feedback to the visual cortex, we propose an intriguing neurosensory account: a feedforward sensory pathway can allow for specialized early threat processing (albeit not the later generalized response), supporting concrete representations of individual threat categories independently and/or interactively with the limbic and prefrontal systems. By this token, the current data would resonate with accruing evidence that threat representation can be stored in the sensory cortex and be activated during basic sensory processing (Weinberger, 2007; Li et al., 2008b; Tsuchiya et al., 2009; Pessoa and Adolphs, 2010; Sacco and Sacchetti, 2010). This idea also echoes long-standing theories of affective primacy (Zajonc, 1984), emphasizing the evolutionary need of quick deciphering of the biological landscape (LeDoux, 1995). Furthermore, fear and disgust, although both threat relevant, are posited to represent independent biological systems-the "selfprotection system" and "the disease avoidance system," respectively (Oaten et al., 2009; Neuberg et al., 2011)—such that they can be endowed with dedicated lines of sensory processing. Given that this early threat specification may similarly underpin other reflexive responses, including opposing autonomic responses for fear and disgust (Levenson, 1992; Bradley et al., 2001), future research is warranted to simultaneously assess early neural processes and peripheral physiological activities (e.g., pupil size or heart rate) to confer additional corroboration.

Nevertheless, this sensory specificity holds only in the first couple tenths of a second, to gradually give way to more general threat processing, at least in a defensive context. While fear response stays above the neutral condition, disgust response appears rather dynamic, rising first above the neutral condition to 
eventually merge with fear response. This intermediate window (130-425 ms) thus bridges early sensory specialization and later perceptual generalization, revealing a systematic progression of threat perception over time. Therefore, to the extent that at a subcortical level later responses to fear and disgust may remain distinct, cortical perceptual analysis of individual threats eventually merge, contributing to congruent perceptual distortions toward a subsequent object.

Visual ERPs to (fully counterbalanced) Greeble objects following fear or disgust images provided supplemental evidence of generalized threat perception at later phases. Convergent P1g and N170 to Greebles in fear and disgust (vs neutral) conditions, along with comparable exaggeration in Greeble proximity estimation, implicate the nondiscriminant influence of threat subtypes on visual processing. To note, these Greeble ERP effects were right hemisphere lateralized, in line with extensive evidence of right hemisphere dominance in threat and face processing (Kanwisher et al., 1997; Davidson et al., 2004). Akin to the account of "defensive distance," object imminence manipulation can effectively provoke the defense system (Schiff et al., 1962; Gibson, 1979; Mobbs et al., 2007), eliciting avoidance behaviors including fight, flight, and freezing (Blanchard and Blanchard, 1988; Fanselow and Lester, 1988; McNaughton and Corr, 2004). Given that fight and flight tend to accelerate and freeze to decelerate reaction speed, the coupling of faster RT with heightened imminence aligns more with fight and flight (than freeze) reactions. Nevertheless, the absence of a clear emotion effect on RT ( $p=0.16$; based on a one-way ANOVA of emotion) suggests that threat moderation of defensive response could be manifold, contributing to a complex combination of active and passive avoidance. Overall, in a defensive context the close mapping between later IAPS ERPs and subsequent Greeble responses (neural and behavioral) highlights nonspecific delayed processing of threat that promotes defensive avoidance rather than rigidly tracking specialized sensory encoding. However, to the extent that specific cognitive mechanisms underlying these consistent IAPS and Greeble effects are highly related, they may not be identical. The later ERPs to threat pictures could reflect (downstream) negative affective and perceptual evaluation, whereas the Greeble visual ERPs may represent (basic) visual attention and monitoring in the presence of biologically salient stimuli.

The current temporal dynamic of threat perception dovetails with our previous functional magnetic resonance imaging data, which similarly revealed a parallel of specific threat representation in the primary sensory cortex and general threat evaluation in the higher-level orbitofrontal cortex (OFC; Li et al., 2008b). As downstream visual perception is informed by both sensory afferents and endogenous feedback modulation, this later convergence across subtypes would very well reflect top-down influence from the OFC that is densely innervated by ventral tegmental dopamine neurons conveying rich motivational information (Lamme and Roelfsema, 2000; Miller and Cohen, 2001; Rolls, 2004). Importantly, this later general enhancement in visual cortical response could also result from reentrant input from the amygdala that is potentiated by threat information (LeDoux, 1995; Tamietto and de Gelder, 2010). Altogether, the current delineation of temporal progression in threat perception provides a viable account unifying subtype-specific reflexes at an early latency with general elaborate/voluntary actions to threat later on (Ratcliff and McKoon, 2008; Jolij et al., 2011).

To the extent that fear of heights makes buildings seem exceedingly high (Stefanucci and Storbeck, 2009) and depression renders a slope to appear dauntingly steep (Riener et al., 2011), threat (fear and disgust alike) heightens the perception of the imminence of a novel object. Whether it is our intention to see what we want to see (Bruner and Minturn, 1955), or that mental and physiological states unconsciously modify our view (Tamietto and de Gelder, 2010), perception, especially threat perception, is intricately tied to motivation. Whereas early threat perception is evolutionarily equipped with stable specification of discrete threats to maintain signal fidelity and incite specific reflexive responses, later threat perception gradually dissociates from early segregation and fuses into general threat response profiles, striking a fine balance between sensory input and biological pressure in the here and now.

\section{References}

Anderson AK, Christoff K, Panitz D, De Rosa E, Gabrieli JD (2003) Neural correlates of the automatic processing of threat facial signals. J Neurosci 23:5627-5633. Medline

Barrett LF, Bar M (2009) See it with feeling: affective predictions during object perception. Philos Trans R Soc Lond B Biol Sci 364:1325-1334. CrossRef Medline

Beck AT, Epstein N, Brown G, Steer RA (1988) An inventory for measuring clinical anxiety: Psychometric properties. J Consult Clin Psychol 56:893-897. CrossRef Medline

Blanchard DC, Blanchard RJ (1988) Ethoexperimental approaches to the biology of emotion. Annu Rev Psychol 39:43-68. CrossRef Medline

Bradley MM, Codispoti M, Cuthbert BN, Lang PJ (2001) Emotion and motivation I: defensive and appetitive reactions in picture processing. Emotion 1:276-298. CrossRef Medline

Bruner JS, Minturn AL (1955) Perceptual identification and perceptual organization. J Gen Psychol 53:21-28. CrossRef

Davidson RJ, Shackman AJ, Maxwell JS (2004) Asymmetries in face and brain related to emotion. Trends Cogn Sci 8:389-391. CrossRef Medline

Desimone R, Duncan J (1995) Neural mechanisms of selective visual attention. Annu Rev Neurosci 18:193-222. CrossRef Medline

Dolan RJ (2002) Emotion, cognition, and behavior. Science 298:1191-1194. CrossRef Medline

Eimer M, Holmes A (2007) Event-related brain potential correlates of emotional face processing. Neuropsychologia 45:15-31. CrossRef Medline

Ekman P, Levenson RW, Friesen WV (1983) Autonomic nervous system activity distinguishes among emotions. Science 221:1208-1210. CrossRef Medline

Fanselow MS, Lester LS (1988) A functional behavioristic approach to aversively motivated behavior: predatory imminence as a determinant of the topography of defensive behavior. In: Evolution and learning (Bolles RC, Beecher MD, eds), pp 185-211. Hillsdale, NJ: Erlbaum.

Forscher EC, Li W (2012) Hemispheric asymmetry and visuo-olfactory integration in perceiving subthreshold (micro) fearful expressions. J Neurosci 32:2159-2165. CrossRef Medline

Garrido MI, Barnes GR, Sahani M, Dolan RJ (2012) Functional evidence for a dual route to amygdala. Curr Biol 22:129-134. CrossRef Medline

Gauthier I, Tarr MJ (1997) Becoming a "Greeble" expert: Exploring mechanisms for face recognition. Vision Res 37:1673-1682. CrossRef Medline

Gibson JJ (1979) The ecological approach to visual perception. New York: Lawremce Erlbaum

Gray JA (1987) Psychology of fear and stress. New York: Cambridge UP.

Jolij J, Scholte HS, van Gaal S, Hodgson TL, Lamme VA (2011) Act quickly, decide later: Long-latency visual processing underlies perceptual decisions but not reflexive behavior. J Cogn Neurosci 23:3734-3745. CrossRef Medline

Kanwisher N, McDermott J, Chun MM (1997) The fusiform face area: A module in human extrastriate cortex specialized for face perception. J Neurosci 17:4302-4311. Medline

Krolak-Salmon P, Hénaff M, Vighetto A, Bertrand O, Mauguière F (2004) Early amygdala reaction to fear spreading in occipital, temporal, and frontal cortex: A depth electrode ERP study in human. Neuron 42:665-676. CrossRef Medline

Krusemark EA, Li W (2011) Do all threats work the same way? Divergent effects of fear and disgust on sensory perception and attention. J Neurosci 31:3429-3434. CrossRef Medline

Lamme VA, Roelfsema PR (2000) The distinct modes of vision offered by 
feedforward and recurrent processing. Trends Neurosci 23:571-579. CrossRef Medline

Lang PJ, Bradley MM, Cuthbert BN (1997) Motivated attention: Affect, activation, and Action. In: Attention and orienting: Sensory and motivational processes. (Lang PJ, Simons RF, Balaban M, eds), pp 97-135. Mahwah, NJ: Erlbaum.

Lang PJ, Bradley MM, Cuthbert BN (2008) International affective picture system (IAPS): Affective ratings of pictures and instruction manual. Technical Report A-8. Gainesville, FL: University of Florida.

LeDoux J (1995) The emotional brain. New York: Simon Schuster.

LeDoux JE (2000) Emotion circuits in the brain. Annu Rev Neurosci 23: 155-184. CrossRef Medline

Levenson RW (1992) Autonomic nervous system differences among emotions. Psychol Sci 3:23-27. CrossRef

Li W, Zinbarg RE, Boehm SG, Paller KA (2008a) Neural and behavioral evidence for affective priming from unconsciously perceived emotional facial expressions and the influence of trait anxiety. J Cogn Neurosci 20:95-107. CrossRef Medline

Li W, Howard JD, Parrish TB, Gottfried JA (2008b) Aversive learning enhances perceptual and cortical discrimination of indiscriminable odor cues. Science 319:1842-1845. CrossRef Medline

Luck SJ (1995) Multiple mechanisms of visual-spatial attention: recent evidence form human electrophysiology. Behav Brain Res 71:113-123. CrossRef Medline

Mangun GR, Hillyard SA, Luck SJ (1993) Electrocortical substrates of visual selective attention. In: Attention and performance XIV (Meyer D, Kornblum S, eds), pp 219-243. Cambridge, MA: MIT.

McNaughton N, Corr PJ (2004) A two-dimensional neuropsychology of defense: fear/anxiety and defensive distance. Neurosci Biobehav Rev 28: 285-305. CrossRef Medline

Miller EK, Cohen JD (2001) An integrative theory of prefrontal cortex function. Annu Rev Neurosci 24:167-202. CrossRef Medline

Mobbs D, Petrovic P, Marchant JL, Hassabis D, Weiskopf N, Seymour B, Dolan RJ, Frith CD (2007) When fear is near: threat imminence elicits prefrontal-periacqueductal gray shifts in humans. Science 317 : 1079-1083. CrossRef Medline

Neuberg SL, Kenrick DT, Schaller M (2011) Human threat management systems: self-protection and disease avoidance. Neurosci Biobehav Rev 35:1042-1051. CrossRef Medline

Oaten M, Stevenson RJ, Case TI (2009) Disgust as a disease-avoidance mechanism. Psychol Bull 135:303-321. CrossRef Medline

Oya H, Kawasaki H, Howard MA 3rd, Adolphs R (2002) Electrophysiological response in the human amygdala discriminate emotion categories of complex visual stimuli. J Neurosci 22:9502-9512. Medline

Pascual-Marqui RD, Esslen M, Kochi K, Lehmann D (2002) Functional imaging with low- resolution brain electromagnetic tomography (LORETA): a review. Methods Find Exp Clin Pharmacol 24:91-95. Medline

Pessoa L, Adolphs R (2010) Emotion processing and the amygdala: from a 'low road' to 'many roads' of evaluating biological significance. Nat Rev Neurosci 11:773-783. CrossRef Medline
Phelps EA (2006) Emotion and cognition: Insights from studies of the human amygdala. Annu Rev Psychol 57:27-53. CrossRef Medline

Pizzagalli D, Koenig T, Regard M, Lehmann D (1998) Faces and emotions: brain electric field sources during covert emotional processing. Neuropsychologia 36:323-332. CrossRef Medline

Ratcliff R, McKoon G (2008) The diffusion decision model: theory and data for two-choice decision tasks. Neural Comput 20:873-922. CrossRef Medline

Riener CR, Stefanucci JK, Proffitt DR, Clore G (2011) An effect of mood on the perception of geographical slant. Cogn Emot 25:174-182. CrossRef Medline

Rolls ET (2004) The functions of the orbitofrontal cortex. Brain Cogn 55: 11-29. CrossRef Medline

Rossion B, Gauthier I, Goffaux V, Tarr MJ, Crommelinck M (2002) Expertise training with novel objects leads to left-lateralized facelike electrophysiological response. Psychol Sci 13:250-257. CrossRef Medline

Rotshtein P, Richardson MP, Winston JS, Kiebel SJ, Vuilleumier P, Eimer M, Driver J, Dolan RJ (2010) Amygdala damage affects event-related potentials for fearful faces at specific time windows. Hum Brain Mapp 31: 1089-1105. CrossRef Medline

Rozin P, Fallon AE (1987) A perspective on disgust. Psychol Rev 94:23-41. CrossRef Medline

Sacco T, Sacchetti B (2010) Role of secondary sensory cortices in emotional memory storage and retrieval in rats. Science 329:649-656. CrossRef Medline

Schiff W, Caviness JA, Gibson JT (1962) Persistent fear responses in rhesus monkeys to the optimal stimulus of "looming." Science 136:982-983. CrossRef Medline

Stefanucci JK, Storbeck J (2009) Don't look down: Emotional arousal elevates height perception. J Exp Psychol Gen 138:131-145. CrossRef Medline

Susskind JM, Lee DH, Cusi A, Feiman R, Grabski W, Anderson AK (2008) Expressing fear enhances sensory acquisition. Nat Neurosci 11:843-850. CrossRef Medline

Tamietto M, de Gelder B (2010) Neural bases of the non-conscious perception of emotional signals. Nat Rev Neurosci 11:697-709. CrossRef Medline

Thatcher RW, North D, Biver C (2005) Evaluation and validity of a LORETA normative EEG database. Clin EEG Neurosci 36:1-8. CrossRef Medline

Tsuchiya N, Moradi F, Felsen C, Yamazaki M, Adolphs R (2009) Intact rapid detection of fearful faces in the absence of the amygdala. Nat Neurosci 12:1224-1225. CrossRef Medline

Vuilleumier P, Pourtois G (2007) Distributed and interactive brain mechanisms during emotion face perception: Evidence from functional neuroimaging. Neuropsychologia 45:174-194. CrossRef Medline

Weinberger NM (2007) Associative representational plasticity in the auditory cortex: A synthesis of two disciplines. Learn Mem 14:1-16. CrossRef Medline

Zajonc RB (1984) On the primacy of affect. Am Psychol 39:117-123. CrossRef 